Janusz Siatkowski

DOI: 10.33896/PorJ.2021.5.5

(Uniwersytet Warszawski,

e-mail: janusz.siatkowski@wp.pl)

ORCID: 0000-0003-4362-9426

\title{
JESZCZE RAZ O POLONIZMACH W SEODKICH SULEJKACH SIEGFRIEDA LENZA
}

O polonizmach w Słodkich Sulejkach Siegfrieda Lenza pisała już Krystyna Pisarkowa [1976]. Wskazała ona na niezwykle silny wpływ polszczyzny w zakresie składni: na szyk orzeczenia podrzędnego w wypowiedzeniu złożonym tuż po podmiocie zamiast na końcu zdania podrzędnego i inne zakłócenia szyku składniowego, a także na opuszczanie podmiotu zaimkowego, który w polszczyźnie może być domyślny. Poza tym zwraca uwage na liczne nazwiska i nazwy miejscowe autentyczne i stylizowane oraz na polonizmy leksykalne cytowane przez S. Lenza ze świadomościa ich obcości, jak np. „seit anno Jagello”, s. $98^{1}$ - pol. „od czasów Jagiełły”, s. 97, czy użyte kilka razy połączenie moja żonka: „Es ist ...moia Zonka, ein Mangel aufgetretten”, s. 75 - pol. „Moja żonkopowiedział - okazało się, że brakuje [gwoździ]”, s. 73, „Die zehn Sätzchen, moia Zonka, die ich sprech' zu dem Baum...”, s. 90 - pol. „Tych dziesięć skromnych zdań, moja żonko, jakie mówię do drzewka...”, s. 88, „Du bist noch jung, moia Zonka...”, s. 91 - pol. „jesteś jeszcze młodziuchna, moja żonko...", s. 89. W powieści Muzeum ziemi ojczystej (Heimatmuseum) zaś używa wyrażenia mój Boże: „moi bosä, flüsterte sie, oh moi bosä”, s. 425, „Wo, moi Bosä, is das Plätteisen?”, s. 542. Zwrot mój Boże (muj Bosche) szczególnie często występuje w utworach Horsta Bienka [Siatkowski 2000, 49-50]. U S. Lenza pojawia się również przekleństwo psiakrew wydrukowane $z$ błędem literowym: „ärgerlich winkte sie mir, komm schon, pschakret", s. 303. Notowano je w dialektach niemieckich szczególnie często, m.in. w Prusach Wschodnich Pschakreff, na Pomorzu Zachodnim Schakreff i na Śląsku psiakrew, a także w utworze Fluch in Erde Bienka Schakreff [Siatkowski 1994, 40; 2000, 48, $100 \mathrm{z}$ dalsza literatura].

Polonizmy w Słodkich Sulejkach omawia też Zbigniew Chojnowski [2014]. Daje zestaw użytych przez S. Lenza imion, nazwisk i nazw miej-

1 Podaję numery stron wydania niemieckiego: Siegfried Lenz, So zärtlich war Suleyken. Masurische Geschichten, Hamburg 1955, a tłumaczenia polskiego w wydaniu: Siegfried Lenz, Słodkie Sulejki, tłum. M. Świętek, Olsztyn 2020. 
scowych o „prusko-polsko-brandenbursko-rosyjskim” brzmieniu oraz elementów „gwary mazurskiej”: Kruschken 'gruszki', fschistko jädno, Lachudders 'lachudry' [Chojnowski 2014, 53, 56].

Do podanych przez K. Pisarkowa i $Z$. Chojnowskiego nazwisk warto dodać Gonsch von Gonschor: „Jagdhaus..., das dem nachmaligen Herrn Gonsch von Gonschor gehörte”, s. 9 - pol. „domek myśliwski..., który należał do późniejszego pana Gasia von Gasiora", s. 7. W. Mitzka [I 360, 438] podaje $z$ dialektów niemieckich na Ślassku Gonsch 'gęś' i Gonschior, Gunschor 'gasior'.

Wieś Sulejki (od stpol. mienia Sut, Sul z bałtyckim sufiksem -eika, -ekis) od dawna istnieje w gminie Świętajno w powiecie oleckim, natomiast przedstawione przez S. Lenza Sulejki stanowia fikcję literacka, mająca prezentować każdą wieś mazurska na tym terenie [por. np. Szcześniak 2014, 277].

Te cenne wcześniejsze opracowania warto uzupełnić przedstawieniem występujących u S. Lenza polonizmów mających bogate poświadczenia $z$ terenu byłych Prus Wschodnich, zwłaszcza $z$ gwar. Swiadczy to bowiem o tym, że były one znane Lenzowi z ówczesnej potocznej pruskiej niemczyzny. Zreszta polskie indywidualizmy w Słodkich Sulejkach zapewne były też szerzej znane w używanym w Ełku lokalnym języku niemieckim.

Siegfried Lenz zresztą używa ich świadomie, co potwierdza zastosowanie zdań o charakterze metatekstowym - polskie połączenia wyrazowe tłumaczone sa przez autora na niemiecki lub podawane sa właściwie jako cytaty, np. „vor dem Gasthaus Tchicha Woda, was sowohl zum stillen als auch zum tiefen Wasser heißen kann”, s. 33 - pol. „przed gospoda Tchicha Woda, co może oznaczać zarówno wodę spokojną, jak i głęboka”, s. 30 (por. sporadycznie na Śląsku tschicho! 'cicho!' [Nyenhuis 2011, 87]), „Hügelchen namens Goronzä Gora, was soviel heißt wie: Heißer Berg”, s. 68 - pol. „uroczy pagórek zwany Goronzä Gora s. 66, „das Bähnchen hinter Goronzä Gora, das ist Heißer Berg, entschwand...”, s. 72 - pol. „jak kolejka znika za Goronzä Gora”, s. 70, „in unmittelbarer Nähe von Goronzä Gora, das ist Heißer Berg” s. 75 - pol. „w bezpośredniej bliskości Goronzä Gora", s. 73.

Pożyczek leksykalnych znanych szerzej w gwarach niemieckich, zwłaszcza zaś na terenie byłych Prus Wschodnich, jest zreszta sporo.

Należy tu Bosniak 'siłacz': „Jetzt wird auftreten ein Mann namens Bosniak, s. 57 - pol. „Teraz wystapi mężczyzna nazwiskiem Bośniak”, s. 55, „kam dieser; ging so, daß die Bänke zitterten”, s. 57 - pol. „wszedł na arenę ów Bośniak; a szedł tak, że ławy drżały", s. 55. Pożyczka ta ma szeroki zasięg w gwarach niemieckich w znaczeniach 'Bośniak, mieszkaniec Bośni', 'wędrowny handlarz bośniacki', 'domokrążca', 'włóczęga', występuje w dialektach pruskoniemieckich głównie w postaci Posnak 'Bośniak' [por. Siatkowski 2015, 63 (z dalszą literatura)]. Poza tym nazwę Bosniaken nosiła uzbrojona w lance elitarna lekka kawaleria pruska, 
która powstała w XVIII wieku. W Mragowie była strażnica bośniacka, w Ełku stacjonował cały regiment Bośniaków. ${ }^{2}$

W opowiadaniach pojawia się także fschistko jädno 'wszystko jedno', 'jednakowo' z pol. wszystko jedno: „Das ist auch, wie man bei uns zu sagen pflegte, fschistko jädno, was soviel heißt wie einerlei", s. 74 - pol. "Zreszta to fschistko jädno, jak zwykło się u nas mówić", s. 72. U S. Lenza występuje też w powieści Muzeum ziemi ojczystej „Fschistko jädno, solange es nötig war”, s. 278. Wyrażenie to zapisywane w różnych postaciach, jako schistko jedno, schiskojeno, schisskojenne, schissskajenno, wschistko jedno, wschistkojedno, w znaczeniu 'wszystko jedno', jest licznie reprezentowane w gwarach niemieckich. Notowano je powszechnie na Śląsku, w Brandenburgii, w Berlinie, w zachodniej Turyngii, w Górnej Saksonii, a nawet w Zagłębiu Ruhry. Pojawia się także w utworach śląskich Horsta Bienka, np. w Septemberlicht „Wschistko jedno, wie man's heißt, sagte Schielok", s. 164, u znanego pisarza Gerharta Hauptmanna, laureata Nagrody Nobla. Wyrażenie to trafiło też do słownika nowoniemieckiego języka potocznego Küppera, a w niemczyźnie wiedeńskiej schetzkojedno 'ts.' jest niezależna pożyczka czes. všecko jedno [por. Siatkowski 2015, 46, 290-291, 374]. W słowniku pruskoniemieckim (PrWb) jednak go nie ma.

Kolejny polonizm to Kruschke 'gruszka', 'grusza': „hier waren es Kastanien, da Kruschken”, s. 95 - pol. „...tu kasztany, tam gruszki”, s. 92, „...abzuscheiden: ...einen Zweig vom Kruschkenbaum”, s. 105 - pol. „i nacięli:..., jedna gałąkę gruszy”, s. 105. Polonizm ten pojawia się również w powieści Muzeum ziemi ojczystej: „es kam aus einer Mulde vor den wilden Kruschkenbäumen", s. 444. Pożyczka ta w gwarach niemieckich ma bardzo szeroki zasięg, przy czym oprócz Kruschke występuja też formy Grauschke, Gruschke. Prześledzenie tych postaci w dialektach niemieckich pozwala nawet na przedłużenie izoglosy wyznaczajacej różnice nagłosu kruszka, gruszka w dialektach słowiańskich. W dawnych dialektach pruskoniemieckich powszechnie występowała Kruschke, głównie w znaczeniu 'dzika gruszka', poza tym też 'szyszka sosny lub jodły' i w różnych znaczeniach przenośnych oraz w licznych złożeniach $z$ wyrazem Kruschke w członie pierwszym lub drugim [por. Siatkowski 2015, 44-45, 303-306, 330].

Polski wyraz pan jako forma grzecznościowa przy zwracaniu się do mężczyzny sporadycznie przejmowany był w gwarach niemieckich. Jego obecność w gwarach Prus Wschodnich zaznaczył S. Lenz: „und vielleicht dürfen wir, Pan Kapitän, um Ruhe bitten”, s. 39. Notuje go np. słownik sudeckich gwar niemieckich [SdW II, 49], występuje powszechnie w twórczości śląskiej Horsta Bienka. Ziesemer 1923, 150-151 podaje z księgi

2 Beitrag zur Geschichte des Preußischen Bosniaken-Corps, vorzüglich über dessen Ursprung und seine ersten Offiziere von Herrn Professor Baczko, Beiträge zum Kunde Preußens, Königsberg 1818, s. 288-302. 
urzędowej Malborka pan 'czcigodny pan' [por. Siatkowski 2015, 326, 380, 402, 405]. Należy tu również wielokrotnie użyty w Sulejkach niejasny zwrot pani pronz, który Pisarkowa 1976, 278 uważa za ponaglenie pany precz lub pany prędzej. W polskim tłumaczeniu utworu podano tu Pan Duma: „In unseren Wäldern beliebte ein Hirsch zu wechseln, daß man ihn pani pronz nannte, was etwa heißt: Herr Stolz", s. $111-$ pol. „Nasze lasy ulubił sobie na miejsce popasu [zamiast: miał zwyczaj zrzucać rogi] pewien jeleń, a był on tak ponad miarę okazały, że nazywano go pan Pronz, co znaczy mniej więcej Pan Duma”, s. 110, „dieser pani pronz, verfügte über eine legendäre Kraft” s. 111 - pol. „miał ów pan Pronz...legendarna siłę", s. 110, „Also drang der Ruhm von pani Stolz, dem Hirsch...bis nach Striegeldorf vor...”, s. 111 - pol. „I tak też sława o panu Stolzu, wspomnianym jeleniu, doszła aż do Striegeldorfu”, s. 110 i podobnie [s. 112, 114, 116].

Sporadycznie występującego u S. Lenza polonizmu Wojwode: „als ob er der Woiwode von Szczylipin selber wäre...” - pol. ,jakby był samym wojewoda ze Szczylipina", s. 8 niezależnie używał często w swoich utworach Horst Bienek: Wojewode o wojewodzie katowickim Michale Grażyńskim, np. „Der Wojewode Grażyński ist durch diesen Aufruf mitgekennzeichnet” - pol. „Apel ten określa również postawę wojewody Grażyńskiego [Polka, 252, por. Siatkowski 2015, 377]. Poza tym Woiwodschaft województwo' podaje ze Śląska Nyenhuis 2011, 233, 257, 275].

Na szczególna uwagę zasługuja dwie polskie pożyczki leksykalne, których $\mathrm{w}$ dotychczasowej literaturze nie wymieniano. S. Lenz przytacza je świadomie jako zapożyczenia, podając, jak zwykle, bezpośrednie tłumaczenie w tekście.

Należy tu Klattkä 'kładka, mostek': „nachdem...ging er an die Klattkä, das ist: ein Steg, heran”, s. 102 - pol. „po czym zbliżył się do kładki”, s. 101, „Katharina machte ihm denn auch schnell Platz auf der Klattkä”, s. 102 - pol. „Katarzyna zrobiła mu też od razu miejsce na kładce”, s. 101. Polonizmu tego w innych źródłach niemieckich nie znalazłem. Może został utworzony na użytek tego opowiadania.

Interesujacy $z$ punktu widzenia kontaktów językowych jest wyraz Lachudder 'oberwaniec, obszarpaniec', 'prostak, cham', dotychczas dokładniej nieomawiany. S. Lenz używa go wielokrotnie: „aber das Lamm, ihr Lachudders: klein, ganz klein, und sauber”, s. 27 - pol. „Bo też jest to Baranek, wy łachudry, maleńki, malusieńki i czysty” , s. 24, „er ging mit ausgebreiteten Armen auf seine Lachudders zu”, s. 27 - pol. „podszedł $z$ roztwartymi ramionami ku tym swoim łachudrom”, s. 24, „stellte ihm der Adam Arbatzki ein Bein, genauer gesagt, stellte dem Lachudder eine Wurzel”, s. 93 - pol. „Adam Arbatzki podstawił mu nogę, mówiąc dokładniej, podstawił temu łachudrze korzeń”, s. 91, „damit ist gemeint das kräftige Bürschchen, Egon Zagel, ein Lachudder weit und breit, worunter man sich vorstellen hat einen Lümmel”, s. 92 - „miała tu na myśli krzepkiego młodzieńca, Egona Zagela, łachudrę, jakich mało, pod którym 
to mianem należy wyobrazić sobie po prostu pewnego nicponia", s. 90. W ostatnim wypowiedzeniu możemy też zauważyć, przedstawione przez K. Pisarkowa, naruszenie obowiazującego w języku niemieckim w zdaniu podrzędnym szyku wyrazów $z$ orzeczeniem na końcu.

W powieści Muzeum ziemi ojczystej pożyczka ta występuje w postaci Lachodder, która słownik pruskoniemiecki [PrWb III, 739-740] określa jako występująca na terenie Prus w rozproszeniu. W powieści tej została użyta kilkakrotnie: „Jieb endlich dem Lachodder, jieb ihm”, s. 71 - pol. 'dołóżcie wreszcie temu łachudrze', s. 62, „da kennte Siechmunt jeden Lachodder vorteilhaft ausstaffieren”, s. 207 - pol. 'Siechmunt mógłby galanto wysztafirować każdego łachudre’, s. 184, „soll ausprobieren, der kleine Lachodder, was er fier sich erkennen kann mit der Zeit”, s. 389 - pol. "niech wypróbuje ten mały łachudra, czego się może $z$ czasem nauczyć dla siebie', s. 344.

Nie jest to innowacja S. Lenza, pożyczka ta była dosyć dobrze znana w dialektach niemieckich na terenie dawnych Prus Wschodnich. Niemiecki słownik pruski notuje zarówno ten wyraz, jak i kilka utworzonych od niego derywatów: Lachudder, sporadycznie Lachodder m.in. 'ulicznik, włóczęga, obszarpaniec, oberwaniec, człowiek źle wygladający' powszechnie $z$ Prus Wschodnich i $z$ delty Wisły, m.in. spod Węgorzewa, Elblaga, znad Niemna. Poza tym znany jest również przymiotnik lachudderig, lachoddrig, lachodrich 'nieporządny, obdarty, obszarpany, zaniedbany', czasownik lachuddern 'iść powoli, opieszale' spod Ełku i pogranicza litewskiego oraz złożenie Lachuddervolk 'motłoch' z pogranicza litewskiego [PrWb III, 739-74].

Na gruncie języka niemieckiego wyraz ten jest niejasny, brak go w niemieckich słownikach etymologicznych. Najpewniej jest to pożyczka dialektyzmu północnosłowiańskiego *lachu-dъra, który F. Sławski [SE IV, 408-409] uważa za złożenie $z$ *lachヶ i *doro o pierwotnym znaczeniu strukturalnym 'człowiek w podartym odzieniu, obszarpaniec'. Wyraz ten występuje w języku polskim oraz jako dialektyzm w białoruskim i rosyjskim. A. Bańkowski [SE, 81] przyjmuje, że pol. łachudra stanowi pożyczkę brus. dial. łachudra, ale zasięg tego wyrazu w gwarach polskich temu przeczy.

SGPK III, 59 notuje łachuder 'oberwaniec' z Lubelszczyzny i łachudra 'oberwaniec', 'nicpoń' z Litwy. W kartotece SGP łachuder 'oberwaniec, obdartus' notowany jest $z$ południowych Kaszub (jako przestarzałe na Zaborach [por. Sychta III, 6]), z Kociewia (też w przysłowiu [SychKoc II, 113]) i z Pelplina koło Tczewa, łachudra 'oberwaniec', 'włóczykij', 'człowiek podły, drań' w rozproszeniu nie tylko ze wschodniej Polski, lecz szerzej z Mazowsza, Małopolski, centralnej Polski (Domaniewek pod Łęczyca), a także $z$ Wielkopolski (spod Konina, Turku i Kalisza). W polszczyźnie ogólnej pojawia się póżno, jeszcze SW II, 185-186 łachuder, łachudra 'obdartus, oberwaniec, obszarpaniec, nędzarz, żebrak' określa jako gwarowy, a dopiero SJPD IV, 242 przytacza formę łachudra jako 
wyraz pospolity i pogardliwy w znaczeniu 'człowiek nędzny, godny pogardy, drań, szubrawiec' z poświadczeniami z roku 1937 [Antoni Słonimski] i 1952 [Jerzy Pytlakowski]. Staje się on powszechny w języku polskim już w okresie międzywojennym. Trudno powiedzieć, czy różniąca się nieco fonetycznie lakudra 'kobieta niewiele warta', występująca powszechnie w Chłopach Reymonta, ma jakiś związek z omawianym tu wyrazem.

Brus. raxýdpa 'człowiek źle ubrany, zaniedbany, nieporządny' ma liczne poświadczenie $z$ gwar. W bogatej dokumentacji w ESBM V, 265, w źródłach pozwalających na ustalenie lokalizacji, można wskazać na okolice Witebska, Mińska, Mohylewa i Homla, w SPZB są natomiast tylko dwa potwierdzenia: $z$ Litwy spod Trok i $z$ terenu Polski $z$ Kuraszewa pod Hajnówka na Białostocczyźnie [SPZB II, 635]. Słownik białoruskiego języka literackiego TSBM wyrazu tego nie notuje. Również tylko gwarowy jest ros. raxýdpa 'oberwaniec' spod Wołogdy i ‘słaby człowiek' spod Jarosławia [SRNG XVI, 297].

A zatem niem. dial. Lachudder 'oberwaniec, obszarpaniec', 'prostak, cham', występujący na rozległym terenie byłych Prus Wschodnich, stanowi pożyczkę polską. Na samej północy może wchodzić w grę również wpływ języka białoruskiego. Dostał się on również do gwar litewskich jako lakudrà 'włóczęga, pijak' [Sławski SE IV, 408-409]. W ten sposób omawiany wyraz tworzy obszerna zwartą wyspę, obejmująca gwary północnej Polski, Białoruś, Litwę i dawne Prusy Wschodnie.

Sposób przytoczenia wyrazu Rachullerigkeit 'zachłanność' z podanym jednocześnie jego tłumaczeniem wydaje się wskazywać na wpływ obcy: „So etwas verhindert unter anderem die Rachullerigkeit - das ist: die Habgier”, s. 88 - pol. „Zapobiega to między innymi zachłanności, to jest obżarstwu”, s. 86. Można przyjąć, że bezpośrednio z polskiego został przejęty najpewniej tylko czasownik rachullen 'wydzierać coś komu' (z pol. rachować stanowiącego pożyczkę zwrotna śrwniem. rechenen), natomiast derywaty, takie jak Rachull, Rachuller 'chciwiec', rachull(e) rig 'chciwy' itd., zostały dotworzone już na gruncie niemieckim [por. Siatkowski 2015, 332].

Na koniec należy zwrócić uwage na skomplikowane połączenia wyrazowe, w których - jak w wypadku wspomnianego już pani pronz-można podejrzewać wpływ polski.

Może należy tu niezbyt jasny zwrot określający czytelniczą pasję głównego bohatera opowiadań z Sulejek, Hamilkara Schassa: „er gehorchte nur mehr einem Gebieter, welchen er auf masurisch den "Zatangä Zitai” zu nennen pflegte, was soviel heißt, wie Leseteufel, oder, korrekter, Lesesatan”, s. 7 - pol. „słuchał teraz jednego władcy, którego zwykł był nazywać po mazursku Zatangii Zitai - albowiem ten to czytelniczy diabel, albo ściślej mówiąc - szatan, go opętał", s. 6. Chyba da się to odczytać jako połączenie catanga c(zy)taj, składające się $z$ cajtunga $z$ niem. Zeitung i pol. czytaj. Pożyczka niemiecka cajtunga 'gazeta' znana jest $z$ kaszubsz- 
czyzny spod Słupska i z Kętrzyna pod Wejherowem, a postać cajtung, cajtunek 'ts.' występuje jeszcze szerzej: na Warmii i Mazurach [SOWM I, 265], a także na Śląsku i na Kaszubach [SGP III, 315].

K. Pisarkowa [1976, 278] tłumaczy zagadkowa formę Kilochen jako wytworzona pod wpływem polskiego wyrazu kilka / kilko. Przytacza wypowiedź Amadeusza Locha do jego żony: „es ist, sagte er, moia Zonka, ein Mangel aufgetreten von einem Kilochen Nägel”, s. 75 - pol. „Zabrakło, moja żonko, kilka gwoździ". W opowiadaniu o wyprawie do Olecka forma ta występuje jeszcze dwukrotnie, poza tym pojawia się w opowiadaniu o wuju Manoahu. Przypuszczenie to jest prawdopodobne, może jednak raczej powstała ona na gruncie niemieckim pod wpływem niemieckich deminutiwów z sufiksem -chen. Tłumaczka Słodkich Sulejek, Marianna Świętek, wszędzie Kilochen tłumaczy przez kilo: „es ist, sagte er, moia Zonka, ein Mangel aufgetreten von einem Kilochen Nägel, s. 75 - pol. „Moja żonko powiedział - okazało się, że brakuje kilo gwoździ”, s. 73, „uns zwingt der Mangel von einem Kilochen Nägel in die Fremde”, s. 75 - pol. „Brak kilograma gwoździ zmusza... do wyjazdu", s. 73, ,...und erwarb natürlich ein Kilochen Nägel in Oletzko”, s. 77 - pol. „i oczywiście nabyto kilo gwoździ w Olecku”, s. 75 oraz „könnte ich es mit einem Kilochen [Maränen], nicht zu knapp, versuchen. Die Frau ...legte zwei Maränen über das Kilo hinzu”, s. 22 - pol. „może bym tak i wział z kilo zważone nie za skapo. Kobieta... dołożyła dwie sielawy ponad kilogram...”, s. 20.

Omówione polonizmy u pochodzacego $z$ Ełku (i honorowego obywatela tego miasta, por. Wielokulturowy świat 2014) Siegfrieda Lenza maja charakter już niedokładnych dawnych wspomnień. Jak wiadomo, jako dziecko rozmawiał on $z$ babka po mazursku, ale później jako dorosły po polsku nie mówił i mimo usilnych starań nie udało mu się opanować języka polskiego [Chojnowski 2014, 56].

Polonizmy te wskazuja jednak wyraźnie na dawna polskość Mazur, na przemożny wpływ polszczyzny na wszystkie warstwy szerzącego się tu wtórnie potocznego języka niemieckiego. Część z nich to wyrazy powszechnie znane w Prusach Wschodnich i moga być wyróżnikiem językowej tożsamości tych terenów, a niektóre sa neologizmami wprowadzonymi na potrzeby danego opowiadania.

\section{Bibliografia}

Bańkowski SE - A. Bańkowski, 2000, Etymologiczny słownik języka polskiego, t. I-II, Warszawa.

Z. Chojnowski, 2014, Polskie czytanie Siegfrieda Lenza (watki wybrane) [w:] J. Ławski, R. Żytyniec (red.), Wielokulturowy świat Siegfrieda Lenza. Studia, Białystok-Ełk, s. 47-66.

ESBM - В.У. Мартынаў, Г.А. Цыхун (рэд.), 1978-, Этьммалагічны слоўнік беларускай мовы, Мінск. 
S. Lenz, 1955, So zärtlich war Suleyken, Masurische Geschichten, Hamburg.

S. Lenz, 2020, Słodkie Sulejki, Olsztyn.

S. Lenz, 1978, Heimatmuseum. Roman, Hamburg.

S. Lenz, 1991, Muzeum ziemi ojczystej, tłum. E. Borg, M. Przybyłowska, Warszawa.

W. Mitzka, 1963-1965, Schlesisches Wörterbuch, t. I-III, Berlin.

A. Nyenhuis, 2011, Deutsche und Polen im Sprachkontakt. Polnische Einflüsse im deutschen Schlesien, Frankfurt am Main.

K. Pisarkowa, 1976, Tak polskie były Sulajki, „Teksty: teoria literatury, krytyka, interpretacja" nr 4-5 (28-29), s. 274-280.

Polka - H. Bienek, (1975) 1987, Die erste Polka, München.

PrWb - Preussisches Wörterbuch, 1974-2005, begr. von E. Riemann, hrsg. von E. Riemann, U. Tolksdorf, R. Goltz, t. I-VI, Neumünster.

SdWb - Sudetendeutsches Wörterbuch. Wörterbuch der Mundarten in Böhmen und Mähren-Schlesien, 1988-, von Ernst Schwarz, betreut von F.J. Beranek, H. Wolf-Beranek, H. Kühnel, N. Englisch, hrsg. von H. Engels, O. Ehrismann, München.

Septemberlicht - H. Bienek, (1977) 1987, Septemberlicht, München.

SGP - Słownik gwar polskich, 1977-, opr. przez Zakład Dialektologii Polskiej Instytutu Języka Polskiego PAN w Krakowie pod kier. Mieczysława Karasia, od t. II pod kier. Jerzego Reichana, od t. VI pod kier. Joanny Okoniowej, od t. IX pod kier. Renaty Kucharzyk, Wrocław-Kraków.

SGPK - J. Karłowicz, 1900-1911, Słownik gwar polskich, t. I-VI, Kraków.

J. Siatkowski, 1994, Słowiańskie wyrażenia $i$ zwroty jako źródła pożyczek w gwarach niemieckich, „Poradnik Językowy” z. 1-2, s. 37-45.

J. Siatkowski, 2000, Slawismen in den schlesischen Romanen von Horst Bienek, München.

J. Siatkowski, 2015, Studia nad słowiańsko-niemieckimi kontaktami językowymi, Warszawa.

SJPD - W. Doroszewski (red.), 1958-1969, Słownik języka polskiego, t. I-XI, Warszawa.

Sławski SE - F. Sławski, 1952-1982, Słownik etymologiczny języka polskiego, t. I-V, Kraków.

SPZB - Ю.Ф. Мацкевіч (рэд.), 1979-1986, Слоўнік беларускіх гаворак паўночна-заходняй Беларусі $і$ яе пагранічча у пяиі тамах, т. I-V, Мінск.

SRNG - Словарь русских народных говоров, 1965-, составиц (с II т. гц. ред.) Ф.П. Филин (Ф.П. Сороколетов), Москва-ценинград-Санкт-Петербург.

SW - J. Karłowicz, A. Kryński, W. Niedźwiedzki (red.), 1908-1927, Słownik języka polskiego, t. I-VIII, Warszawa (tzw. Słownik warszawski).

SychKoc-B. Sychta, 1980-1985, Słownictwo kociewskie na tle kultury ludowej, t. I-III, Wrocław.

B. Sychta, 1967-1976, Słownik gwar kaszubskich na tle kultury ludowej, t. I-VII, Wrocław.

K. Szcześniak, 2014, Świat roślin w Słodkich Sulejkach Siegfrieda Lenza [w:] J. Ławski, R. Żytyniec (red. nauk.), Wielokulturowy świat Siegfrieda Lenza. Studia, Ełk-Białystok, s. 277-292.

TSBM - K.К. Атраховіч (Кандрат Крапіва) (рэд.), 1977-1984, Тлумачальны слоўнік беларускай мовы, t. I-V, Мінск. 
Wielokulturowy świat 2014 - J. Ławski, R. Żytyniec (red. nauk.), Wielokulturowy świat Siegfrieda Lenza. Studia, Ełk.

W. Ziesemer, 1923, Beobachtungen zur Wortgeographie Ostpreussens, „Zeitschrift für deutsche Mundarten" t. XVII, s. 149-160.

\section{Once again about polonisms in Stodkie Sulejki by Siegfried Lenz}

\section{Summary}

The polonisms present in the text of Słodkie Sulejki, a book by Siegfried Lenz, clearly indicate the former Polishness of Masuria, the considerable influence of the Polish language on the colloquial variant of German recurring in this region. S. Lenz did not speak Polish and therefore the polonisms in his artistic idiolect are a certain language reminiscence from his childhood, when he spoke the Masurian dialect with his grandmother.

Keywords: language contacts - artistic language - polonisms in German Siegfried Lenz.

Trans. Monika Czarnecka 